\title{
A Prediction Algorithm for Cloud Integrated Smart Parking System to Search Vacant Parking Spot using Internet of Things
}

\author{
Sifat Rahman Ahona \\ Computer Science and Engineering \\ American International University-Bangladesh \\ (AIUB) \\ Dhaka, Bangladesh
}

\author{
Naima Hassan \\ Computer Science and Engineering \\ East West University \\ Dhaka, Bangladesh
}

\begin{abstract}
In recent years it has been observed that the approach of smart city has been increased. It is because of the growing portion of IoT devices for consumers. In order to boost the productiveness and authenticity of metropolitan framework persistent attempts are being made in the field of IoT. Traffic congestion, Road blockage, restricted parking and road safety are some issues that has come forward in IoT. In this paper, a single platform smart parking system integrated to cloud based on IoT is presented. The proposed Smart Parking system comprises certain inventive technologies that can administer car parking automatically. This research also proposes a prediction algorithm to improve efficiency of searching and booking of vacant parking spot and also implements a prototype with Wi-Fi access on a single platform established on Arduino where using a smart phone the system and the vehicle will get an interface to validate the workability of the proposed system.
\end{abstract}

\section{General Terms}

Internet of things

\section{Keywords}

IOT, Smart parking, wireless, applications, Cloud.

\section{INTRODUCTION}

Everyone who has ever been disappointed driving around metropolitan zones looking for parking has desired a solution that could rapidly lead them to that elusive location. It has been found in a recent research that a driver takes almost 8 minutes to park his vehicle as he invests more time searching the parking garage. This searching leads to thirty to forty percent of traffic congestion [1].

At present, the frequently used method to find parking space is not automated and most of the time user rely on their previous experience. The process of finding parking space gets worst in places where vehicle density is large. One solution is to find a car parking with large capacity. Nonetheless, as the car park might be far from user destination this cannot be considered as an ideal solution. Lately, it has been observed that different technologies of wireless network such as radio frequency identification (RFID), Wireless mesh network has been used to develop interaction between automobile to automobile and automobile to framework. The goal of this research is to give user information about free parking in a nearby place considering road congestion and reserve the space some time earlier through one single platform using their smartphones or other devices. Nevertheless, the present smart parking system available does not give a perfect solution to search a free parking space as this system does not provide solution to some problems such as road congestion, cost effectiveness, and vehicle-denial.

In the proposed system every space is considered as an IoT network and also stored the vehicle's GPS location, length between car parking and the car, quantity of the free parking space will be updated on cloud automatically whenever a parking becomes free or booked. It used a Geolocation Service that calculates the cost of a parking request in terms of distance and time, and this cost is updated periodically and are reachable anytime in the network by the vehicles.

The smart parking system is based on certain inventive technologies that is able to administer car parking automatically. It implements a prototype with Wi-Fi access on a single platform established on Arduino using a smart phone that will supply the system and the vehicle an interface to validate the workability. Moreover, in proposed model, each car parking can work individually as a conventional parking system. The smart parking system not only provides benefit to the driver but also beneficial to the managers who manages the parking sports as it maintains a reservation system. Because of the reservation system user can make a reservation earlier before coming to the spot using the proposed app. In contrast to traditional parking system this smart parking system has considerable amount of benefit. Here driver gets the information about the state of the parking space in period manner. Not only that this process also helps the manager of the parking space to utilize the space properly. This paper has suggested an architecture of a smart parking where a prediction algorithm has been introduced.

\section{RELATED WORK}

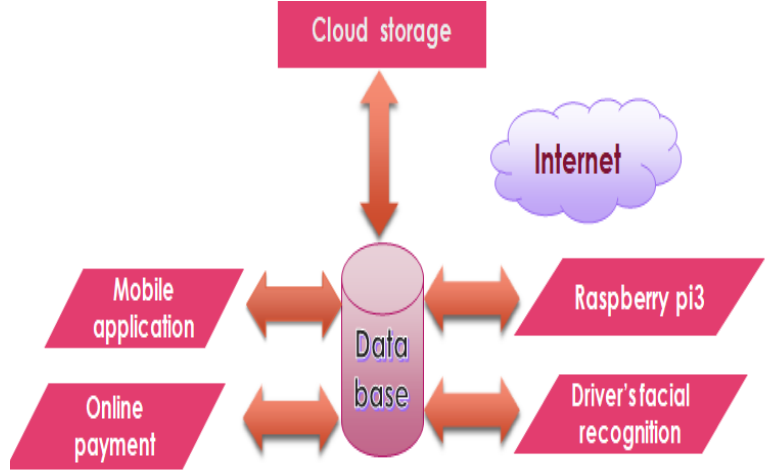

Fig 1: Architecture and working system [2] 
In the paper [2], the authors did not measure the efficiency of the parking services, presented no mathematical model of the system and did not think about the service waiting time of each vehicle. Some portion of this framework is applied in the Zigbee network, which sends vital information via a coordinator to a PC and updates the database afterwards. The application layer will rapidly pass the parking info over the Internet, and utilize the benefits of a web service to collect all the information on dispersed parking for the solace of the people who need to find a parking spot. This paper reports simply on the design and implementation of a smart parking system and does not evaluate the system performance.

Here, the client needs to enroll their information to the server through application. After the information are entered, he is permitted to sign in to his record, and book an opening for his vehicle. At the time of booking the user is given a token for fifteen minutes to enter place his vehicle in the accurate place. Before entering into the parking space, the number plate is crossed checked with the previous given information. This whole work is done using Raspberry pi3 camera.

Distributed computing and IoT have seen enormous advancement. Both the advances have their points of interest, anyway a few shared preferences can be predicted from their combination. On one hand, IoT can address its mechanical requirements [3]. Fundamentally, the Cloud goes about as a middle of the road among things and applications, so as to conceal all the complexities and functionalities that are necessary for the application to run. The following are a portion of the elements that prompted the incorporation of Cloud and IoT [4].

Storage Capacity: IoT involves countless data sources (things), which generate gigantic measures of non-organized or semi-organized information. As a result, IoT requires gathering, getting to, handling, imagining and sharing a lot of information. The information put away on the Cloud can be gotten to and imagined from anyplace through standard APIs [4].

Computation power: The tools used within IoT have minimal processing capability. Collected data from different sensors are normally transmitted to more efficient nodes, where they can be aggregated and processed using Cloud's on-demand and processing capabilities [4].

Communication resources: IoT's main functionality is to allow IP-enabled devices communicate with each other by means of dedicated hardware collection [4].

Scalability: Cloud offers an approach that is scalable to IoT. It allows dynamic fashion of increases or decreases in resources.

Availability: With cloud integration anywhere at any time the availability of resources becomes very easy. Many of the cloud suppliers guarantee 5 nine availability [4].

Interoperability: IoT includes the use of heterogeneous tools of a type. Such devices may have different configurations of hardware or software which trigger compatibility problems [4].

Other researchers have also designed parking infrastructure systems in smart cities. Barone et al. [5] proposed an intelligent parking assistant (IPA) architecture intended to solve existing public parking management solutions. This architecture offers drivers with knowledge about availability of on-street parking spaces and helps drivers to book the most convenient parking spaces at their destination before their departure. For the system architecture, this study [6] uses only a few basic mathematical equations and does not generate a large-scale parking scheme. In other works, authors invented and incorporated a smart parking scheme whose bottom part is composed of ZigBee network which sent pressure information to PC through a coordinator and then update database.

Zhao and Hai [7] proposed a parking planning approach which could provide vehicles with timely and effective guidance for real-time smart parking systems. By holding parking queries in a waiting line for a while, authors turn parking planning into a kind of linear assignment problem.

In another study Mainetti et al. [8], proposed a smart parking system grounded on the incorporation of IEEE 802.15.4 Wireless Sensor Network technologies, UHF frequency and RFID. The structure can gather data on the car park occupancy status and can guide drivers to the nearest empty parking space using a software application. Nevertheless, the authors do not provide any mathematical equations for the system architecture in this work.

Hsu et al. [9] proposed an inventive system including the parking guidance service. A parking space can be allocated via the Internet through a smartphone. The reserved parking space will be shown on a small map when entering the car park using wireless transmission for vehicles under the DSRC licensed short-range communication protocol. In order to direct the automobile to the reserved space an inertial navigation system (INS) is introduced.

The main purpose of the IOT-based Smart Parking System is to monitor the devices' status via server (Wi-Fi). The system's entire controlling device is a Microcontroller. The Microcontroller is interacted by Wi-Fi module, IR sensors. The IR sensors are fed to the Microcontroller as input. This data is processed by the Microcontroller and transmitted via Wi-Fi, which will be obtained from MOBILE. To accomplish the task, a program written using Embedded $\mathrm{C}$ language is loaded to the controller. Through password the user who wants to park the vehicle is connected to that particular parking lot's Wi-Fi network. The IR sensors submit the status to the microcontroller which processes the data. The microcontroller sends information about slot status to the web page using IOT. This way the user can locate a parking slot conveniently in less time and without any congestion [10].

\section{COMPONENTS}

Arduino UNO R3: The Arduino UNO R3 is a microcontroller board based on an ATmega328 AVR microcontroller with removable, dual-inline package (DIP). It has 20 digital input/output pins (6 of which can be used as PWM outputs and 6 can be used as analog inputs). The R3 is Arduino's third, and most recent, revision. The Arduino UNO board is a microcontroller built on the ATmega328. Out of its 14-digital input/output pins 6 can be used as PWM outputs, an ICSP header, a $16 \mathrm{MHz}$ ceramic resonator, 6 analog inputs, a USB connection, a reset key and a power cable.

IR SENSOR: An IR sensor is an electronic device that emits some aspects of the environment to be sensed. An IR sensor can calculate an object's heat and can also sense the motion. These types of sensors measure only IR radiation, rather than emitting it that is called as a passive IR sensor. IR sensor works to detect a specified light wavelength in the Infra-Red spectrum using a specific light sensor. By using a LED that emits light at the same wavelength as the sensor, one can look at the intensity of the light obtained. 
Servo motor: A servo motor is an electric device that can precisely move or rotate an object. If one wishes to rotate and object at a certain angle or distance, then use servo motor. It's just a simple motor that runs through the mechanism of the servo.

LCD display: It has two registers which are command and data. The select register is used to switch from one register to another. The data is the character's ASCII value that must be DISPLAYED on the LCD. Once data is sent to LCD it goes to the data register and is treated there. When $\mathrm{RS}=1$, data register is selected.

NodeMCU: The NodeMCU (Node Microcontroller Unit) is an open source software and hardware development platform designed around a very low-cost on-a-chip (SoC) system named ESP8266, Wi-Fi module chip that can be configured to access the internet for Internet of Things (IoT) and similar technology projects. Generally, one cannot connect your usual electrical and mechanical equipment to the Internet alone.

\section{PROPOSED MODEL}

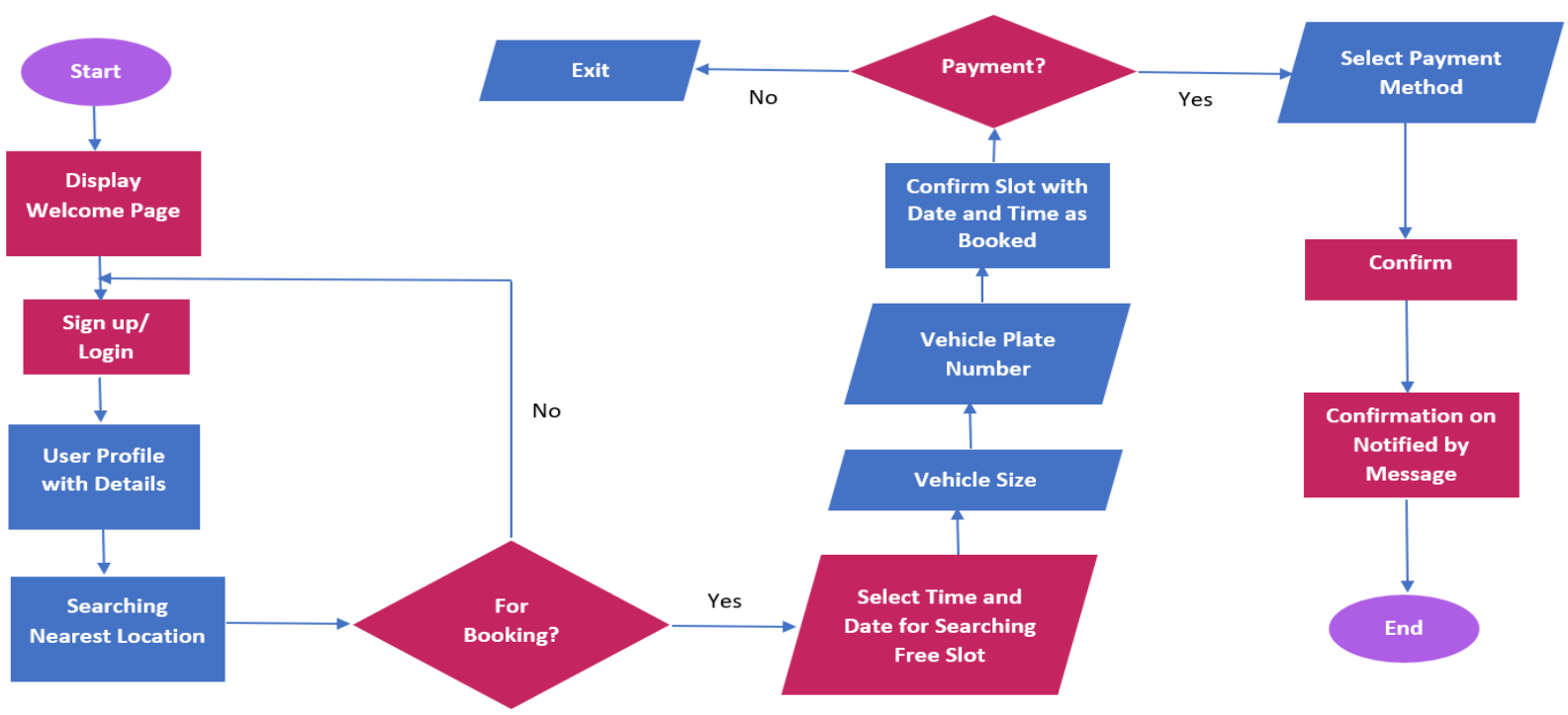

Fig 2: Online booking system flowchart

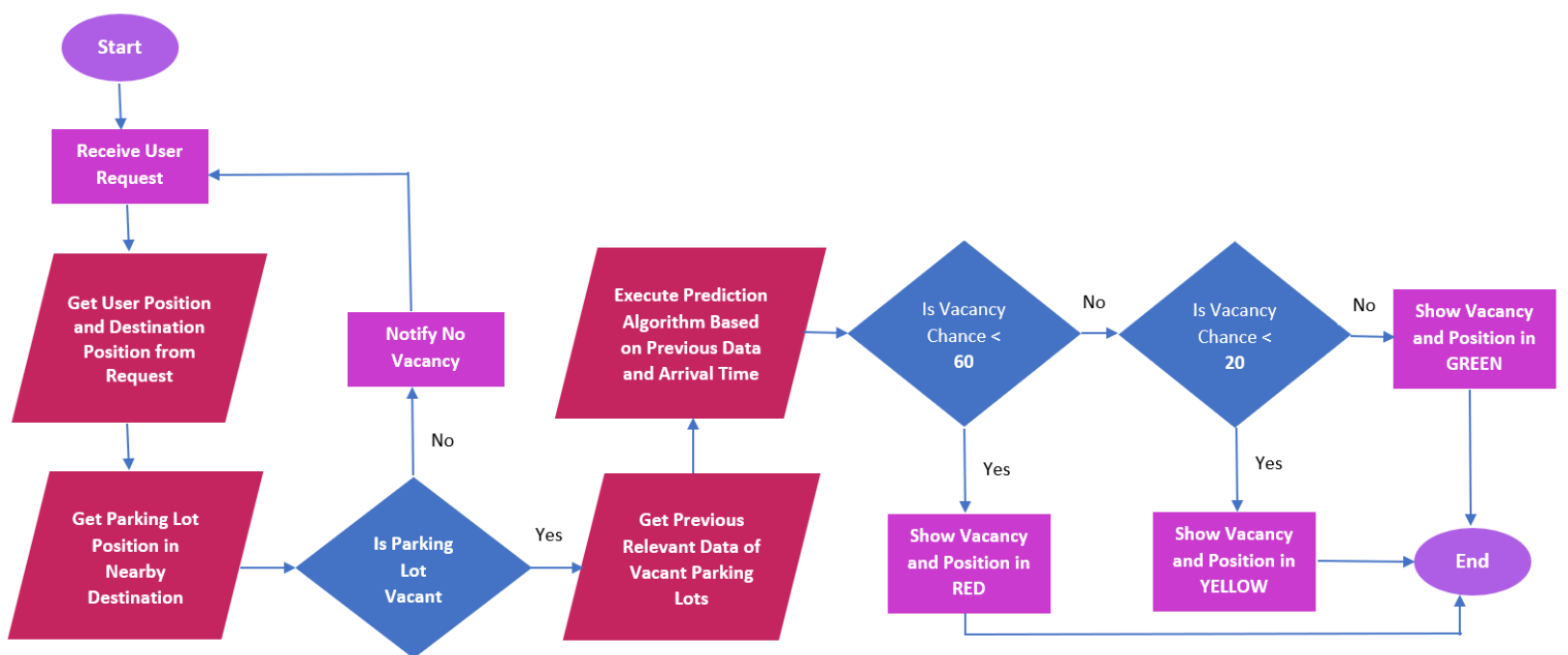

Fig 3: Flowchart of Prediction Algorithm

In this figure 2, flow chart of the application procedure is given. When a driver requests nearest parking locations of his destination, application gets time, day, destination, location, vehicle size and number plate from the request. Application will search for free parking space in destination locations and will calculate reaching time, show number of free space and provide booking option for each parking space. If user books a parking space he/she will then have to pay the parking fee in advance via online transaction (example: bKash or Debit Card or Credit Card). Application will contact the parking space authority and book a place for the user. Each parking locations maximum capacity is given before, so this system can compare it with the car number count to calculate vacancy in the parking area. The application will calculate the distance between the user and the parking area nearby the user.

However, there may arise some issue in the proposed system such as if a user books for a parking space and then don't show up in the parking space. In such case user will lose money also the parking spot will not be vacant for other users. Some user might not be comfortable with advanced booking system also. So, the authors introduced a prediction algorithm which will increase efficiency and make the application more useful. 
The flow chart in figure 3 shows the working procedure of prediction Algorithm. Prediction algorithm will use historical data of parking spots such as car entry and leave, time to reach the destination from the location from where request was sent. Prediction algorithm will also consider weather and national events as parameters to predict vacancy available.

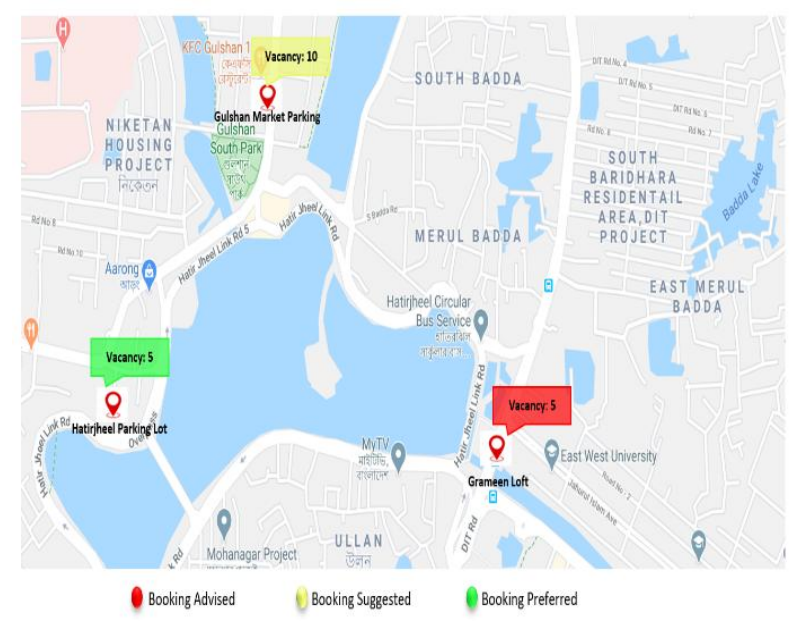

Fig 4: Prediction Algorithm scenario

The figure 4 will help illustrating the use of prediction algorithm. Now imagine a scenario where a user requests for parking space around Gulshan. Here you can see Grameen loft and Hatirjheel parking lot have same amount of vacancy but analyzing previous data prediction algorithm suggest that the Grameen loft might not be vacant when the user reaches at the place but Hatirjheel parking lot will probably be vacant for the user. Gulshan DCC parking might be vacant by the time user reaches the place but chances are lower than Hatirjheel parking lot even though Gulshan DCC parking have more space vacant.

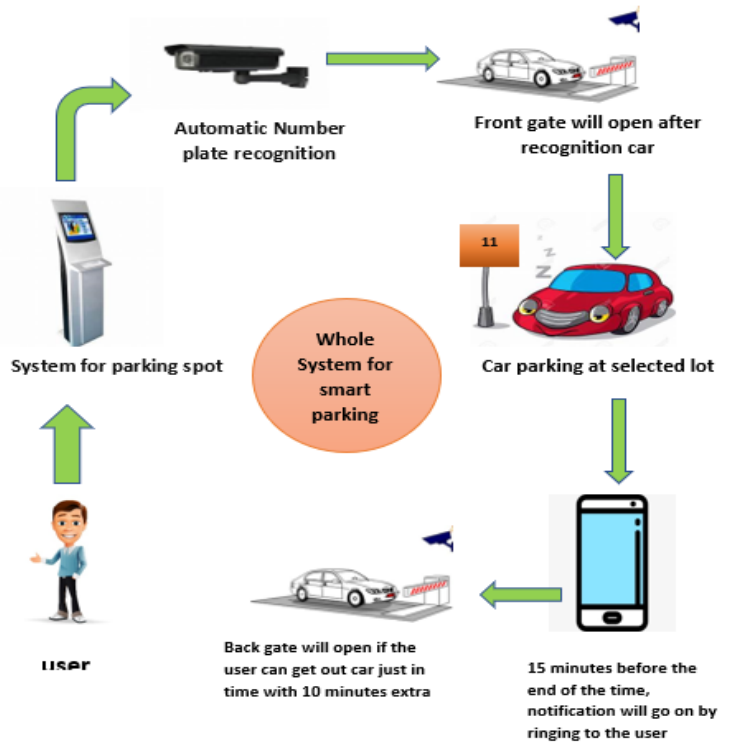

Fig 5: Smart parking system infrastructure

Figure 5 shows that the architecture of the smart parking system. Without booking user are not be able to park their car in the parking area. This is not only for online booking but also for traditional parking where booking is done instantly. First user needs to punch their driving license for activating booking system. System will check the validity of the license than user will be able to select the date and time for searching free slot. After slot selection system will ask the user to give car information, user contact number and other necessary information. Then user will select car type and give the number of car recognition plate shown below in figure 6 .
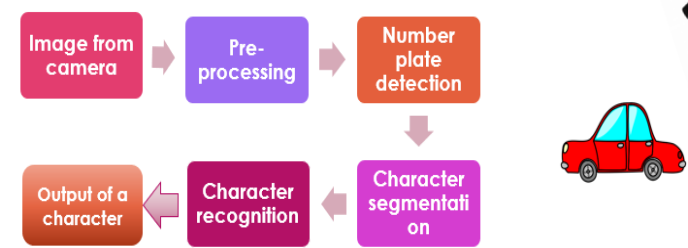

Fig 6: Automatic number plate recognition system

After that system will show the parking charge. Later successful completion of the payment the automatic number plate recognition will be done, and user will be allowed to enter the parking area. The car will be able to enter the parking spot 10 minutes before the scheduled time. Then the user will park their car at the selected slot for requested amount of time. The application will give a notification to the user 15 minute prior to the expiry time. After that back gate will be open for that specific car for 10 minutes. If the user fails to maintain this time frame he will be charged extra for that specific time duration. The flow chart below explains the work flow of the application from user registration for booking a parking space.

\section{IMPLEMENTATION AND WORKING}

\subsection{Circuit Diagram}

This is the circuit diagram of hardware implementation. In this hardware this circuit diagram has used. ARDUINO UNO R3, jumpers, LCD display, SURVO motor, bread board, and 6 IR sensors is used for this implementation. Six IR sensor's positive pins, SURVO motor's positive pins and LCD display's positive pins have been connected on breadboard through ARDUINO UNO R3'S VCC. The negative pin's connected with ARDUINO UNO R3'S ground. Six IR sensor's and SURVO motor's signal pins connected with ARDUINO UNO R3; S signal pins like 6,7,8,9,10,11,12. And LCD displays SDA and SCL pins connected ARDUINO UNO R3'S SDA and SCL pins.

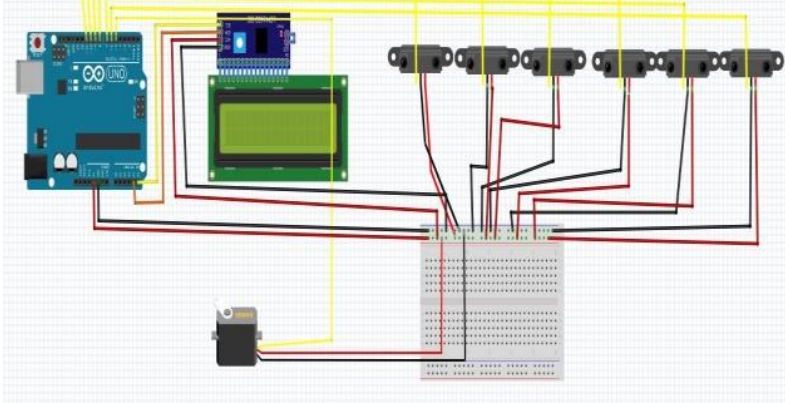

Fig 7: Circuit diagram of hardware implementation

\subsection{User Interface and Design}

It shows how user will communicate through application in figure 8 . 

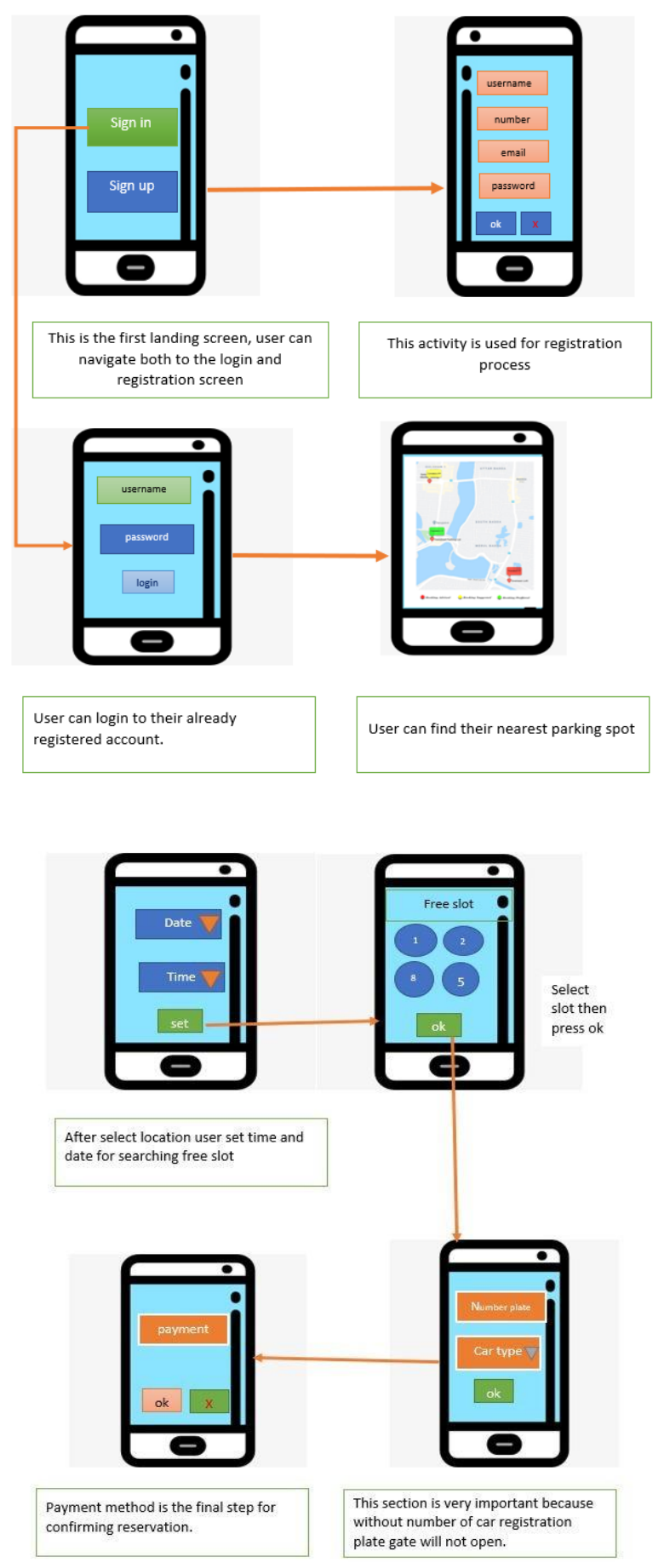

Fig 8: Displays the user interface and design

\section{DISCUSSION AND ANALYSIS}

The proposed system will store the entry and exit time for each vehicle. Thus, with the help of parking duration and exceed time total payable amount will be charged.

\section{1 unit=30 mins}

Per unit time $=\mathrm{x}$ unit money

Exceed Time $=(1-29)$ mins $\rightarrow 30$ mins

1 exceed unit time $=2 \mathrm{x}$ unit money [double from initial]

Minimum booking = 1-unit time
Table 1. Analyzing data following proposed methodology

\begin{tabular}{|c|c|c|c|c|c|}
\hline $\mathrm{V}_{\mathrm{i}}$ & Initial Duration & Entry Time & Exit Time & Exceed Time & Total Charge \\
\hline $\mathrm{V}_{0}$ & 2 unit & $13: 00$ & $14: 00$ & 0 unit & $2 \mathrm{x}$ \\
\hline $\mathrm{V}_{1}$ & 4 unit & $08: 25$ & $10: 50$ & 1 unit & $4 \mathrm{x}+2 \mathrm{x}$ \\
\hline $\mathrm{V}_{2}$ & 3 unit & $19: 20$ & $20: 15$ & -1 unit & $3 \mathrm{x}-\mathrm{x}$ \\
\hline $\mathrm{V}_{3}$ & 1 unit & $02: 00$ & $02: 30$ & 0 unit & $\mathrm{x}$ \\
\hline $\mathrm{V}_{4}$ & 5 unit & $15: 05$ & $16: 35$ & -2 unit & $5 \mathrm{x}-2 \mathrm{x}$ \\
\hline $\mathrm{V}_{5}$ & 1 unit & $21: 45$ & $23: 15$ & 2 unit & $\mathrm{x}+4 \mathrm{x}$ \\
\hline $\mathrm{V}_{6}$ & 1.5 unit & $16: 30$ & $17: 15$ & 0 unit & $\mathrm{x}+\mathrm{x} / 2$ \\
\hline $\mathrm{V}_{7}$ & 2.5 unit & $07: 15$ & $09: 00$ & 1 unit & $4 \mathrm{x}+\mathrm{x} / 2$ \\
\hline
\end{tabular}

*If the Exceed Time is negative then reduce regular price.

Here three case studies have been presented to calculate the total cost by varying distance, traffic congestion and parking availability. From the prediction algorithm, system will get the state of parking availability. Then the system will recommend the optimal parking destination for the user based on the cost which is lower. But when cost will be equal, the system will recommend the parking destination by distance.

- $\quad 1$-unit distance $=1 \mathrm{~km}$ Cost: 2 points

- Traffic condition

$$
\begin{aligned}
& \text { high } \rightarrow 5 \text { points } \\
& \text { moderate } \rightarrow 3 \text { points } \\
& \text { low } \rightarrow 1 \text { point }
\end{aligned}
$$

- Parking Availability Condition from previous data

$$
\begin{aligned}
& \text { Pick } \rightarrow 10 \text { points } \\
& \text { Off pick } \rightarrow 5 \text { points }
\end{aligned}
$$

- Tie Breaker

$$
\text { distance }
$$

Case 1:

node source: [no of destination 2]

Table 2. Data for case 1

\begin{tabular}{|c|c|c|c|}
\hline Destination & Distance & Traffic Condition & Parking Availability \\
\hline$d_{1}$ & $2 \mathrm{~km}$ & Moderate & Pick \\
\hline $\mathrm{d}_{2}$ & $3 \mathrm{~km}$ & High & Pick \\
\hline
\end{tabular}

Cost for distance $=\mathrm{C}_{1}$

Cost for traffic condition $=\mathrm{C}_{2}$

Cost for parking availability $=\mathrm{C}_{3}$

Total $\cos \mathrm{t}=\mathrm{C}_{\mathrm{t}}$

Table 3. Calculating total cost for case 1

\begin{tabular}{|c|c|c|c|c|}
\hline Destination & Cost-1 $\left[\mathrm{C}_{1}\right]$ & Cost-2 $\left[\mathrm{C}_{2}\right]$ & Cost-3 $\left[\mathrm{C}_{3}\right]$ & Total Cost $\left[\mathrm{C}_{\mathrm{t}}\right]$ \\
\hline $\mathrm{d}_{1}$ & 4 & 3 & 10 & 17 \\
\hline $\mathrm{d}_{2}$ & 6 & 5 & 10 & 21 \\
\hline
\end{tabular}

$C_{t}$ for $d_{1}<C_{t}$ for $d_{2}$

Decision: go to destination 1

Case 2:

node source: [no of destination 2] 
Table 4. Data for case 2

\begin{tabular}{|c|c|c|c|}
\hline Destination & Distance & Traffic Condition & Parking Availability \\
\hline $\mathrm{d}_{1}$ & $1 \mathrm{~km}$ & high & Pick \\
\hline $\mathrm{d}_{2}$ & $3 \mathrm{~km}$ & low & Off pick \\
\hline
\end{tabular}

Cost for distance $=\mathrm{C}_{1}$

Cost for traffic condition $=\mathrm{C}_{2}$

Cost for parking availability $=\mathrm{C}_{3}$

Total $\cos \mathrm{t}=\mathrm{C}_{\mathrm{t}}$

Table 5. Calculating total cost for case 2

\begin{tabular}{|c|c|c|c|c|}
\hline Destination & Cost-1 $\left[\mathrm{C}_{1}\right]$ & Cost- $2\left[\mathrm{C}_{2}\right]$ & Cost-3 $\left[\mathrm{C}_{3}\right]$ & Total Cost $\left[\mathrm{C}_{\mathrm{t}}\right]$ \\
\hline $\mathrm{d}_{1}$ & 2 & 5 & 10 & 17 \\
\hline $\mathrm{d}_{2}$ & 6 & 1 & 5 & 12 \\
\hline
\end{tabular}

$C_{t}$ for $d_{1}>C_{t}$ for $d_{2}$

Decision: go to destination

Case 3:

node source: [no of destination 2]

Table 6. Data for case 3

\begin{tabular}{|c|c|c|c|}
\hline Destination & Distance & Traffic Condition & Parking Availability \\
\hline $\mathrm{d}_{1}$ & $2 \mathrm{~km}$ & Moderate & Pick \\
\hline $\mathrm{d}_{2}$ & $3 \mathrm{~km}$ & Low & Pick \\
\hline
\end{tabular}

Cost for distance $=\mathrm{C}_{1}$

Cost for traffic condition $=\mathrm{C}_{2}$

Cost for parking availability $=\mathrm{C}_{3}$

Total cost $=\mathrm{C}_{\mathrm{t}}$

Table 7. Calculating total cost for case 3

\begin{tabular}{|c|c|c|c|c|}
\hline Destination & Cost-1 $\left[\mathrm{C}_{1}\right]$ & Cost-2 $\left[\mathrm{C}_{2}\right]$ & Cost-3 $\left[\mathrm{C}_{3}\right]$ & Total Cost $\left[\mathrm{C}_{\mathrm{t}}\right]$ \\
\hline $\mathrm{d}_{1}$ & 4 & 3 & 10 & 17 \\
\hline $\mathrm{d}_{2}$ & 6 & 1 & 10 & 17 \\
\hline
\end{tabular}

$C_{t}$ for $d_{1}=C_{t}$ for $d_{2}$

Decision: go to destination 1 as $\mathrm{C}_{1}<\mathrm{C}_{2}$

\section{CONCLUSION}

From the emergence of industrialized cities, vehicles are most commonly used element of day-to-day life. And the most common issues with it to find available parking in the nearest place. If available how long will it take to reach the place. If one reaches the place will the parking be still available for them? With the increasing number of cars and insufficient parking spaces [11] people are facing traffic problems much more than the previous era. This parking crisis scenario prompts new solutions with the proposed method and prediction. This algorithm gives all the solutions with the proposed smart parking system using internet of things.

\section{REFERENCES}

[1] Walvekar, M. O., Kulkarni, M. A., Waghmode, M. A., \& Mane, M. R. (2017). Automatic Car Parking.

[2] E.Cassin Thangam, M.Mohan, J.Ganesh, C.V.Sukesh, IOT based smart parking reservation system using Rasberry-pi,2018,International Journal of Applied Engineering Research,2015.

[3] J. Cynthia, C. Bharathi Priya, P. A. Gopinath, IOT based Smart Parking Management System, November 2018, IJRTE.

[4] Abhirup Khanna, Rishi Anand, IOT based Smart Parking System,2016(IOTA)Maharashtra Institute of Technology.

[5] Y. Geng and C. G. Cassandras, _A new _smart parking 'system based on optimal resource allocation and reservations, "in Proc. 14th Int. IEEE Conf. Intell Transp. Syst. (ITSC), Oct. 2011, pp. 979-984.

[6] Y. Geng and C. G. Cassandras, _New _smart parking 'system based on resource allocation and reservations, “IEEE Trans. Intell. Transp. Syst., vol. 14, no. 3, pp. 1129-1139, Sep. 2013.

[7] X. Zhao, K. Zhao, and F. Hai, _An algorithm of parking planning for smart parking system, "in Proc. 11th World Congr. Intell. Control Autom. (WCICA), 2014, pp. $4965-4969$

[8] L. Mainetti, L. Palano, L. Patrono, M. L. Stefanizzi, and R. Vergallo, Integration of RFID and WSN technologies in a smart parking system, "in Proc. 22nd Int. Conf. Softw., Telecommun. Comput. Netw. (SoftCOM), 2014, pp. 104-110.

[9] C. W. Hsu, M. H. Shih, H. Y. Huang, Y. C. Shiue, and S. C. Huang, _Verification of smart guiding system to search for parking space via DSRC communication, "in Proc. 12th Int. Conf. ITS Telecommun. (ITST), 2012, pp. 77-81.

[10] Dr Y, Raghvender in ECE Dept, Automatic smart parking system using IOT, JNTUHCEJ, Telagana.

[11] Nazish Fatema, Akshaya Natkar, Pratiksha Jagtap, S. T. choudhari, IOT based Smart Parking System for smart Cities. 